\title{
Sports medicine in the Netherlands: a long road to a new start
}

Sports medicine has been recognised as a medical specialty in the Netherlands since 1987. During this time 55 specialists have entered the register and another 25 are in training at the Netherlands Institute of Sports Medicine (NIOS). In December 1997, a report was published in which it was calculated that 120 full time working sports medicine specialists are required in the Netherlands. The wish of many to work part time means that there is an overall need for 145 specialists. Therefore the NIOS decided early in 1998 to increase the number of students trained per annum from six to between eight and ten.

The model used to calculate the number of full time sport medicine specialists required is based on the fact that these specialists are working in regional hospitals affiliated to sports medical advice centres. At present, only eight sport medicine specialists work in hospitals, all other work being carried out in other locations. However, a rapid change can be expected. This change will be a major one for the Dutch sports physician, who is still considered to be a specialist in social medicine, like medical specialists in occupational and community medicine. Specialists in social medicine form a separate group in the Dutch health care and medical system: they do not work in hospitals and they do not have a working budget or a contract with sick funds or insurance companies. Even a pricing system to bill their work is not available. The new work place of sports physicians in the hospital will change all this, starting with or finalised by a switch to the register of clinical medical specialists.

In order to achieve this switch, the Dutch Sports Medicine Association has started a dialogue with the clinical specialists, who have agreed to recognise sports medicine as a clinical specialty as soon as the Association has clearly defined its area of science. To do this, the Board of the
Dutch Sports Medicine Association recently appointed several task forces. The scientific committee will continue to work on the definition of sports medicine and to explore its scientific basis. New scientific studies will be initiated and carried out. In order to describe the role of sports medicine specialists in the hospital, clinical multidisciplinary protocols will be developed in collaboration with staff in associated specialties such as physiotherapy.

In the mean time, interesting progress has been made: sports medicine has become part of basic medical training at some universities, and is now included in post graduate training for general practitioners. Also cardiologists, orthopaedic surgeons, and general practitioners spend some of their CME time on sports medicine.

The Board also decided that the scientific journal of the Association, Geneeskunde en Sport, will play a more important role during and also after the transition period. Consequently, the journal has recently introduced a column written by the President of the Dutch Sports Medicine Association and intends to publish more clinically oriented case studies, as well as short single case reports, along with the original scientific work. It will also act as a platform for dispensing information to members of the Association, as well as reporting on scientific developments in sports medicine in general.

Little by little, but on many fronts at the same time all moving in the same direction, Dutch sports medicine is becoming more professional and will, it is hoped, be recognised as a clinical specialty in the near future. This will not be the end of all the effort, just a new start in a different world.
President, Dutch Association for Sports Medicine

JAN AGHINA

Send orders to John H Clegg JP BSc LDS RCS Eng, Hon Secretary, Birch Lea, 67 Springfield Lane, Eccleston, St Helens, Merseyside WA10 5HB, UK. (Tel: 01744 28198)

\section{BASM Merchandise 1999}

$\begin{array}{lll}\text { Ties } & \text { Single motif } & £ 6+£ 1.50 \mathrm{p} \& \mathrm{p} \\ & \text { Multi motif } & £ 6+£ 1.50 \mathrm{p} \& \mathrm{p} \\ \text { Blazer badge } & \text { Wire }-4 \text { inches high } & £ 5+£ 1.50 \mathrm{p} \& \mathrm{p} \\ & \text { Wire }-3 \text { inches high } & £ 5+£ 1.50 \mathrm{p} \& \mathrm{p}\end{array}$

New stock to order

Sweaters

Lambswool fine knit, V-neck or round

$£ 32+£ 3 p \& p$

neck with small motif. Machine washable.

Sweatshirts

With small motif.

State colour and chest size required.

Polo shirts

With small motif.

$$
£ 25+£ 3 \text { p\&p }
$$$$
£ 23+£ 3 p \& p
$$

State colour and chest size required.

Some education polo shirts in cream

and grey are also available at the same price. 